\title{
Educação inclusiva na Tailândia: Perspetivas de Futuros Professores
}

\author{
Inclusive education in Thailand: Perspectives from future teachers
}

\author{
Ana Paula Martins, Ph.D.*; Sasinan Sirithadakunlaphat, Ed.D.** \\ *Centro de Investigação em Educação, Instituto de Educação, Universidade do Minho, Portugal; \\ **Faculdade de Educação, Universidade Burapha, Tailandia
}

\begin{abstract}
Resumen
Este artigo apresenta os resultados de uma investigação levada a cabo e na Tailândia sobre as perspetivas de futuros professores. Seguindo uma metodologia quantitativa, os dados foram recolhidos através de um questionário junto de 221 estudantes universitários que frequentavam cursos de formação de professores numa universidade na Tailândia, em 2015. Os resultados descritivos e inferenciais mostram que: 1) mais de metade dos futuros professores que participaram neste estudo têm uma atitude positiva em relação à inclusão na classe regular; 2) Os futuros professores têm atitudes mais positivas relativamente aos benefícios da inclusão para as famílias e para a comunidade do que para os alunos e professores. Adicionalmente, as atitudes em relação à inclusão foram influenciados pela severidade das necessidades educativas especiais, ou seja, as atitudes são mais positivas à medida que a severidade diminui; 3) Existe uma atitude muito positiva em relação à ideia de que as pessoas com necessidades especiais têm o direito de serem incluídas na comunidade tailandesa. Neste artigo são discutidas as implicações desses resultados para educação dos alunos com necessidades educativas especiais na Tailândia.
\end{abstract}

Palabras clave: Educação inclusiva internacional; investigação quantitativa; necessidades educativas especiais.

\section{Enquadramento}

Neste texto de atas optámos por indicar apenas os resultados relativos ao contexto Tailandês. Assim, começamos por caracterizar a educação inclusiva na Tailândia e de seguida por apresentar e discutir os resultados de uma pesquisa quantitativa realizada no contexto da formação de professores.

Globalmente, a filosofia e a prática da filosofia da inclusão de alunos com necessidades educativas especiais em salas de aula regulares tem vindo a ser implementadas, o que implica que aumentou significativamente o número destes alunos que são incluídos no sistema regular de ensino (Correia \& Martins, 2000). Na verdade a escola deve apresentar-se como um local diversificado, que responde às necessidades, e apoia as diferenças e a aprendizagem de "todas as crianças, independentemente das suas condições físicas, sociais, linguísticas ou outras"
(Unesco, 1994, p. 6). Está aqui incluída uma diversidade de alunos, nomeadamente alunos em risco educacional, alunos sobredotados e alunos com NEE. Estes últimos podem, durante todo ou parte do seu percurso escolar, necessitar de um atendimento prestado pelos serviços de educação especial "destinados a responder às necessidades do aluno, com base nas suas características, e com o fim de maximizar o seu potencial" (Correia, 2008, p. 40). Segundo Salend (1998, p. 7) a inclusão "constitui um movimento de famílias, professores e membros da comunidade, com vista à criação de escolas e outras instituições sociais, baseadas na aceitação, pertença, e sentido comunitário" (p. 7). Segundo Correia (2008) o conceito de inclusão refere-se à "inserção do aluno com necessidades educativas especiais, em termos físicos, sociais e académicos nas escolas regulares" ( $p$. 20).

A legislação relativa à educação de alunos com necessidades educativas especiais na Tailândia é recente, pelo que este país está ainda a dar os seus passos na implementação de uma educação inclusiva e, portanto, está ainda a transitar da ideia para a implementação (Vorapanyaa \& Dunlap, 2014). Em 1999 a Tailândia aprovou legislação nacional que garantia a defesa dos alunos com NEE a uma educação básica pública grátis (Office of Special Education Administration, 2014) e em 2008 uma lei específica para as necessidades educativas especiais, que indica os seguintes direitos destes alunos: a) a partir do nascimento ou do momento do diagnóstico e ao longo da vida, têm direito a uma educação grátis e a receber materiais tecnológicos e educativos; 2) devem ter oportunidade de frequentar uma escola de acordo com as suas características, interesses, pontos fortes e necessidades; 3 ) devem receber uma educação com um alto nível de qualidade, em instituições acreditadas, incluindo um desenho curricular apropriado e uma avaliação às suas necessidades especiais (Office of Special Education Administration, 2015).

Segundo Bualar (2015) na Tailândia os professores não têm ainda a formação necessária para apoiar e ensinar os alunos com necessidades educativas especiais. De facto, segundo resultados da investigação o conhecimento sobre e como apoiar os alunos com necessidades educativas especiais adquirido ao longo da frequência de cursos de formação de professores é um fator importante para melhorar as atitudes dos professores na implementação de práticas inclusivas na sala de aula (Avramidis \& Norwich, 2010). Adicionalmente, tal como Niemeyer e Proctor (2002) 
sublinham, a importância do desenvolvimento de atitudes positivas acerca da inclusão ao longo dos cursos de formação de professores não pode ser relegada para segundo plano porque as atitudes dos professores influenciam a implementação de práticas inclusivas. Os resultados de vários estudos realizados em países como os EUA, a Austrália, o Reino Unido e Portugal tendem a enfatizar que a formação em necessidades educativas especiais está associada a uma menor resistência destes às práticas inclusivas (Avramidis \& Norwich, 2010; Correia \& Martins, 2000). De facto, a investigação citada por Martins (2011), mostra que existe um conjunto de pressupostos para o sucesso da filosofia da inclusão, entre eles a formação de professores, que se constituem como partes interdependentes da criação de uma comunidade educativa interessada, dinâmica, flexível e de sucesso.

Neste contexto, e considerando que os professores do ensino regular desempenham um papel importante na implementação da educação inclusiva, realizamos um estudo que teve por finalidade conhecer as atitudes de futuros professores tailandeses sobre o tema da inclusão de alunos com necessidades educativas especiais na escola regular. Os objetivos deste estudo foram dois. O primeiro foi descrever as atitudes dos futuros professores em relação ao ambiente menos restritivo, ao benefício e ao impacto da inclusão de alunos com necessidades educacionais especiais em escolas regulares e na comunidade. O segundo foi o de identificar significância estatística entre as variáveis género e experiência do contato com crianças com necessidades educativas especiais ou adultos com deficiência.

\section{Método}

\section{Participantes}

Participaram neste estudo 221 estudantes dos cursos de formação de professores numa Universidade na Tailândia. Os estudantes tailandeses têm uma média de idades de 21 anos, 34 deles frequentavam o $2^{\circ}$ ano, 117 o $3^{\circ}, 35 \circ 4^{\circ}$ ano e 34 o $5^{\circ}$ ano do curso de formação de professores. Na sua maioria são do gênero feminino e nunca contactaram com crianças ou adultos com necessidades especiais (apenas oito participantes indicaram ter tido esta experiência). De sublinhar que todos frequentaram uma unidade curricular sobre NEE.

\section{Instrumento de Recolha de dados}

Neste estudo utilizamos como instrumento de recolha de dados o questionário denominado "Perceção dos Professores sobre a Inclusão de alunos com NEE", desenvolvido na Universidade do Minho por Martins e Santos (2012), traduzido e adaptado para Tailandês. O questionário tem duas partes. Uma primeira parte que se relaciona com aspetos demográficos e experiencias na área das necessidades educativas especiais e uma parte com e uma segunda parte constituída por 21 itens que identificaram as diferentes atitudes dos participantes sobre inclusão utilizando uma escala de Likert com quatro possibilidade de escolha: Discordo totalmente, discordo, concordo e concordo plenamente.

\section{Procedimentos}

Os dados foram recolhidos durante as últimas duas semanas do mês de Maio e primeira de junho de 2015, após os participantes terem assinado um termo de consentimento e de esclarecimento. Utilizamos estatística descritiva e inferencial (testes paramétricos, teste $t$ e One-way Anova, para $p \leq 0,05)$ para tratamento de dados e delineamento de resultados que apresentamos de seguida.

\section{Resultados}

No que respeita a atitudes sobre o ambiente menos restritivo possível (AMRP) para os alunos com NEE a maioria dos participantes (188) tendem a concordar e concordar totalmente com a ideia de os alunos necessidades educativas especiais serem educados em escolas especiais (ver Figura 1).

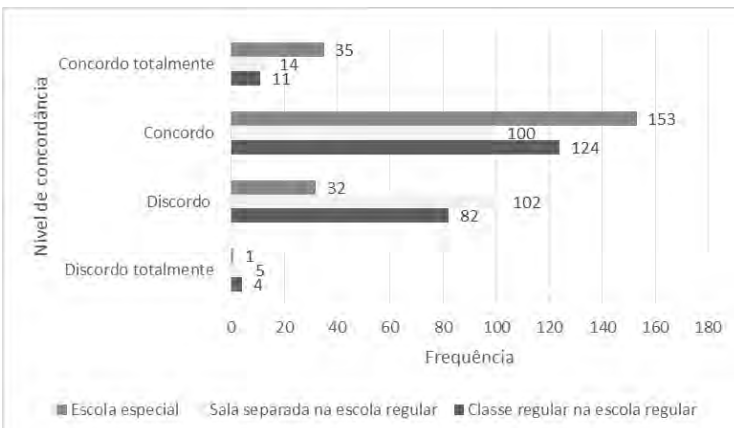

Figura 1. Resultados para o AMRP

Tal como se observa na Figura 2, um maior número de participantes tendem a concordar que a inclusão é benéfica para as famílias dos alunos com NEE (173) e para a comunidade (166), do que a concordar que esta prática é benéfica para os alunos com necessidades educativas especiais (163), para professores (146) ou para os colegas (140).

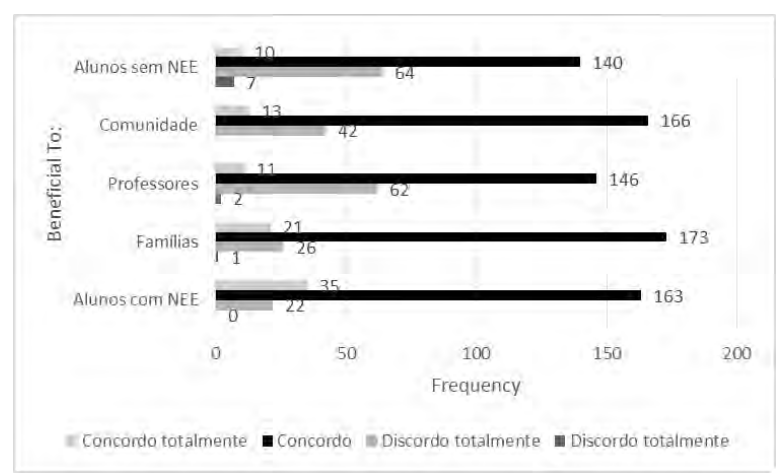

Figura 2. Resultados sobre quem beneficia da inclusão

De sublinhar que para metade dos futuros professores a colocação de um aluno com necessidades educativas especiais numa classe regular perturba os seus colegas.

As atitudes em relação à inclusão foram influenciados pela severidade das NEE, ou seja, as atitudes são mais positivas à medida que a severidade diminui (ver Figura 3). 


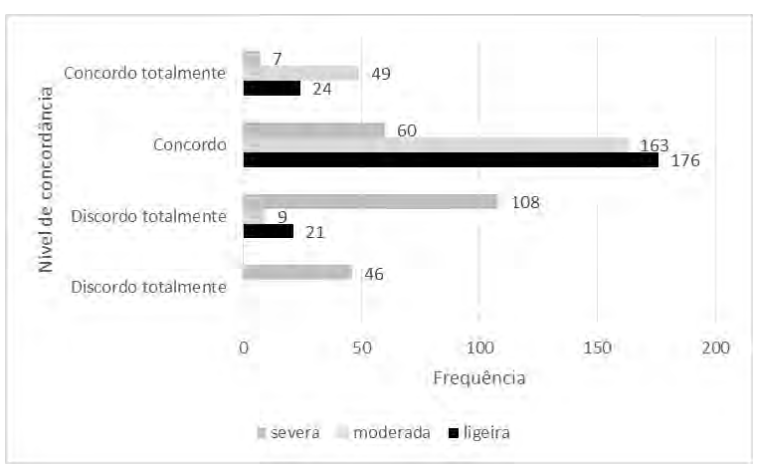

Figura 3. Resultados para os benefícios da inclusão segundo a severidade das necessidades educativas especiais

Por fim, salientamos que os futuros professores apresentam uma atitude mais positiva em relação ao benefício da inclusão no desenvolvimento social do que no desenvolvimento acadêmico destes alunos.

A análise inferencial dos dados indica que as variáveis gênero e contato com crianças com necessidades educativas especiais ou com adultos com deficiência não tiveram significado estatístico. Contudo, as raparigas apresentam atitudes ligeiramente menos positivas relativamente à inclusão sendo elas que mais concorda com a frequência de escolas especiais e atitudes ligeiramente mais positivas no que diz respeito aos benefícios da inclusão para os alunos com NEE e suas famílias; enquanto os rapazes têm atitudes mais positivas no que diz respeito os benefícios para os colegas, os professores e da comunidade. Além disso, aqueles que raramente estão em contacto com esta população são os que têm atitudes mais positivas relacionadas com a inclusão, enquanto os que declararam estarem sempre em contacto com as crianças com necessidades educativas especiais tiveram as atitudes menos positivas.

Por fim, os resultados mostram que existe uma atitude muito positiva em relação à ideia de que as pessoas com necessidades especiais têm o direito a serem incluídas na comunidade tailandesa ( 80 dos participantes pesquisados concordam e 136 concordo totalmente). O alfa de Cronbach para estes resultados foi de 0.81 , o que indica uma boa consistência interna.

\section{Discussão}

Tal como referido por Correia (2008), todo o sistema de educação público deve assegurar que as crianças, e jovens, independentemente da severidade das suas necessidades educativas especiais, tenham uma educação pública gratuita e apropriada. Segundo Correia (1997), uma educação apropriada tem como premissa básica "a resposta às necessidades educativas do aluno, proporcionando-lhe experiências que se construam a partir das suas realizações iniciais, com o fim de maximizar as suas aprendizagens (académicas e sociais)" (p. 14). Esta educação apropriada e inclusiva implica vários pressupostos entre eles a formação de professores, que entre outros aspetos contribui para a formação de atitudes positivas em relação à inclusão. Tendo por base os resultados deste estudo gostaríamos de sublinha os seguintes três aspetos: 1) mais de metade dos futuros professores que participaram neste estudo têm uma atitude positiva em relação à inclusão na classe regular. Segundo princípios morais, legislativos e humanos o aluno com NEE deve ser educado tanto quanto possível, junto dos alunos sem NEE, ou seja, no meio menos restritivo possível. $\mathrm{O}$ conceito de meio menos restritivo possível considera que o aluno, sempre que possível, deve ter a oportunidade de frequentar a escola da sua zona de residência e de interagir com os seus vizinhos e os outros membros da comunidade (Salend, 1998, citado por Martins, 2000). 2) Os futuros professores têm atitudes mais positivas relativamente aos benefícios da inclusão para as famílias e para a comunidade do que para os alunos e professores. Adicionalmente, as atitudes em relação à inclusão foram influenciados pela severidade das necessidades educativas especiais, ou seja, as atitudes são mais positivas à medida que a severidade diminui. $\mathrm{O}$ impacto das práticas inclusivas é multifacetado para a comunidade educativa e para a sociedade em geral. A investigação sobre estes benefícios, contudo, tem-se revelado contraditória, pelo que, tanto os opositores, como os defensores da integração e da inclusão, encontram resultados que sustentam o seu ponto de vista (Lipsky \& Gartner, 1997; Salend, 1998, citados por Martins, 2000). Os defensores da inclusão consideram que esta filosofia tem bastantes vantagens; nomeadamente:

- Reduz o estigma associado aos alunos com necessidades educativas especiais;

- Encoraja a colaboração entre o professor titular de turma e o professor de educação especial;

- Estimula o aumento dos conhecimentos do professor titular de turma, no que respeita às intervenções, às estratégias, e às adaptações curriculares a utilizar junto dos alunos com necessidades educativas especiais;

- Reduz a necessidade de rotulagem;

- Aumenta as interações entre alunos com, e sem, necessidades educativas especiais, beneficiandoos a todos;

- Adaptase aos diferentes níveis de ensino, incluindo o superior;

- Tem por base um modelo de colaboração/consultadoria, que encoraja a existência de um professor que atende as necessidades de uma população heterogénea. São, assim, beneficiados, não só os alunos com necessidades educativas especiais mas, também, aqueles que se encontram em risco educacional (Huefner, 1988, citado por Smith et al., 1995). Por outro lado, existem profissionais e pais que não apoiam a inclusão, considerando que:

- Os professores titulares de turma não estão suficientemente envolvidos no processo de implementação de um modelo inclusivo, nem sentem que têm formação suficiente para o fazer;

- Não existe colaboração entre o professor titular de turma e o professor de educação especial;

- Estas práticas diminuem a qualidade da educação dos alunos sem NEE;

- Há poucos dados empíricos que apoiem o modelo inclusivo; 
- O financiamento, e a formação dos professores, baseiase na dualidade de sistemas;

- A qualidade da educação de alguns alunos com necessidades educativas especiais aumenta, quando estes frequentam classes especiais (Smith et al., 1995). Para mais informação sobre resultados de investigações acerca do impacto da integração, e da inclusão, nos alunos com, e sem, NEE, nos professores titulares de turma, e nos de educação especial, nos pais, e na sociedade em geral ler Martins (2000). 3) Por fim, salientar que existe uma atitude muito positiva em relação à ideia de que as pessoas com necessidades especiais têm o direito de serem incluídas na comunidade tailandesa.

Estes resultados resultam de um estudo único que foi realizado com uma amostra de alunos de uma universidade, pelo que seria interessante conduzir-se um estudo nacional sobre a atitude não só dos futuros professores mas igualmente daqueles que já exercem a profissão nas escolas tailandesas.

\section{Referencias}

Avramidis, E. \& Norwich, B. (2010). Teachers' attitudes towards integration / inclusion: a review of the literature. European Journal of Special Needs Education, 17(2), 129-147, http://dx.doi.org/10.1080/08856250210129056

Bualar, T. (2015). What has gone wrong with inclusive education in Thailand? Journal Public Affairs, online early view, http://dx.doi.org/10.1002/pa.1563

Correia, L.M. (2008). Inclusão e necessidades educativas especiais: Um guia para educadores e professores. Porto: Porto Editora.

Correia, L.M. \& Martins, A.P.L. (2000). Uma escola para todos: Atitudes dos professores perante a inclusão. Revista Inclusão, 1, 15-29.

Niemeyer, J.A. \& Proctor, R. (2002) The influence of experience on student teachers' beliefs about inclusion. Journal of Early Childhood Teacher Education, 23(1), 49-57, http://dx.doi.org/10.1080/1090102020230109

Martins, A. P.L. (2000). Martins, A. P. L. (2000). O movimento da escola inclusiva: Atitude dos professores do $1^{o}$ Ciclo do ensino básico. Tese de mestrado, Universidade do Minho, Braga, Portugal.

Martins, A. P.L. (2011). A Inclusão de alunos com necessidades educativas especiais na escola regular: A filosofia e os elementos para o sucesso. In F. A. T., Costa (Eds.), Educação, educação especial e inclusão: Fundamentos, contexto e práticas (pp.39-53). Curitiba, Brazil: Appris. ISBN 978-85-64561-55-7.

Office of Special Education. (2015). Documentation for training. The development of educational master classroom (inclusive school). Bangkok: Author.

Office of Special Education (2014). The result of the development of for model inclusive education in schools ( $2^{\text {nd }}$ ed $)$. Bangkok: Author.

Salend, S. J. (1988). Understanding mainstreaming and inclusion. Englewood Cliffs: Prentice Hall.

Vorapanya, S. \& Dunlap, D. (2014). Inclusive education in Thailand: practices and challenges. International Journal of Inclusive Education, 18(10), 1014-1028, http://dx.doi.org/10.1080/13603116.2012.693400

UNESCO (1994). The Salamanca statement and framework for action on special needs education. Acesso em setembro 7, $2010 \mathrm{em}$ : http://unesdoc.unesco.org/images/0009/000984/09842 7eo.pdf 